\title{
ARTE_PESQUISA: INTER-RELAÇÕES
}

Este dossiê da revista ARS reúne textos apresentados no evento ARTE_PESQUISA: INTER-RELAÇÕES promovido pelos três Programas de Pós-Graduação em Artes e Artes Visuais do Estado de São Paulo: o Programa de Pós-Graduação em Artes da UNESP, sob coordenação da Profa. Rejane Coutinho; o Programa de Pós-Graduação em Artes Visuais da USP, sob coordenação da Profa. Monica Tavares; e o Programa de Pós-Graduação em Artes Visuais da UNICAMP, sob coordenação do Prof. Mauricius Farina.

ARTE_PESQUISA: INTER-RELAC̣ÕES pretendeu incentivar e estreitar o intercâmbio acadêmico entre os três programas de pós-graduação, ao mesmo tempo em que procurou aprofundar o debate sobre as pesquisas em desenvolvimento. Configurou-se como um fórum privilegiado de discussão acerca das relações entre a criação e a investigação em arte. Os eixos temáticos tratados foram os seguintes: Poéticas e Linguagens, História, Teoria e Crítica da Arte e Arte-educação.

\section{Programa do evento}

Dia 9 de outubro

Palestra de abertura: Edmond Couchot - L'Université Paris VIII / FR

Mediação: Gilberto dos Santos Prado - ECA-USP / BR

Mesa-redonda: Carlos Zílio - UFRJ / BR e François Soulages - L'Université

Paris VIII / FR

Mediação: Sônia Salzstein Goldberg - ECA-USP / BR

Dia 10 de outubro

Mesa-redonda: Lúcia Gouvêa Pimentel - UFMG / BR e Bernard Darras

L'Université Paris I / FR

Mediação: Ana Mae Barbosa - ECA-USP e Universidade Anhembi Morumbi / BR

Mesa-redonda: Luiz Sérgio de Oliveira - UFF / BR e Francisco Laranjo Universidade do Porto / PO

Mediação: Mauricius Farina - IA-UNICAMP / BR

Dia 11 de novembro

Mesa-redonda: Monica Tavares - ECA-USP / BR, Mauricius Farina - IA-UNI-

CAMP - BR e Rejane Coutinho - IA-UNESP BR 
0 evento aconteceu de 9 a 11 de outubro de 2012, no Instituto de Artes da UNESP, São Paulo/SP, no formato de comunicações, palestra de abertura e mesas-redondas. Personalidades nacionais e estrangeiras, de reconhecida competência na área de artes, foram convidadas para participar da programação a seguir exposta. Com esta edição, a ARS trata, portanto, de colocar à disposição dos leitores alguns dos textos dos pesquisadores convidados e participantes do evento organizado pelos Programas de Pós-Graduação em Artes e Artes Visuais vinculados às três Universidades públicas do Estado de São Paulo.

Os artigos trazem à luz as reflexões desses professores acerca das relações entre arte e pesquisa.

Edmond Couchot discute a influência das ciências cognitivas sobre as teorias da arte e da estética, no artigo "As ciências cognitivas e a pesquisa na criação artística e a estética".

François Soulages problematiza as inter-relações possíveis e existentes entre a pesquisa filosófica e a arte, no texto "0 filósofo \& a arte".

No trabalho intitulado "Inters_tícios - inter_tiscos”, Lúcia Pimentel levanta questões a respeito dos vínculos entre arte, pesquisa e ensino, na pressuposição de que o estabelecimento de conceitos em rede abrem possibilidades de convergência de conhecimentos e potencialidades de expansão para o artista contemporâneo.

No artigo "Pesquisa em arte por ocasião dos doutorados baseados na prática um estudo do caso da Universidade de Paris 1 Sorbonne", Bernard Darras aborda criticamente o sistema de doutoramento colocado em prática na Sorbonne desde os anos 1970, examinando os dispositivos científicos e artísticos implantados e as limitações e os problemas daí gerados.

Francisco Laranjo cogita sobre o universo da criação e da investigação contemporâneas nas instituições universitárias e museológicas, no texto "Investigação e arte: enunciação e propósitos".

Por fim, no trabalho denominado "A mundanidade da arte", Luiz Sérgio de Oliveira examina como o processo de recuperação do sentido público da arte requer a redefinição de todo o seu sistema - produção, circulação, consumo, instituições e crítica da arte -, o que sugere a necessidade de revisão de certitudes institucionais e, consequentemente, da reinvenção da arte considerada como produto do encontro entre o artista e o "outro".

Em sua maioria, são textos que nos fazem ponderar e meditar sobre as superposições entre as noções de pesquisa como processo e de pesquisa como qualificação. Trazem como objetivo o questionamento de como se configura a pesquisa acadêmica em arte.

\section{Monica Tavares}

